\title{
ON CRITICAL PARAMETERS OF PHOTONUCLEAR ISOTOPE PRODUCTION
}

\author{
V.L. Uvarov \\ National Science Center “Kharkov Institute of Physics and Technology”, Kharkiv, Ukraine \\ E-mail: uvarov@kipt.kharkov.ua
}

Analytical model for description of isotope generation in a thick production target exposed to no uniform flux of high-energy bremsstrahlung radiation is developed. A set of principal process parameters determinative the yield of a product isotope and distribution of its specific activity has been established. It is shown, that as those parameters may be the yield of the product isotope in a thin foil overlapping the photon flux, normalized to the mass thickness of the foil (a coefficient of photonuclear conversion), and also the standard radial deviation of the flux density of the above-threshold photons at the target as well as the most probable angle of their escape from a bremsstrahlung converter. The methods for measuring those parameters are proposed. Testing of the model was conducted using the ${ }^{100} \mathrm{Mo}(\gamma, \mathrm{n}){ }^{99} \mathrm{Mo}$ reaction by comparing the results obtained from the model consideration with the data of experimental study and computer simulation. The proposed approach enables the optimization of photonuclear technology as respects to target dimensions and activation regime.

PACS: 07.05.Tr, 41.50.+h; 41.75.Fr; 78.70.En

\section{INTRODUCTION}

Manufacturing of isotopes with the use of highenergy bremsstrahlung radiation of electron accelerator is believed as possible alternative to reactor and, in some cases, to cyclotron technologies (see e.g. [1, 2]). The advantages of photonuclear isotope production lie in its relatively low cost and environmental safety. At the development of such a technology, one of issues is the optimization of geometry and irradiation mode of a thick production target by preliminary estimation of the yield of a product isotope.

As an example, the volumetric distribution of the Mo-99 nuclei generated with the X-ray beam having end-point photon energy of $40 \mathrm{MeV}$ in a cylindrical molybdenum target via the ${ }^{100} \mathrm{Mo}(\gamma, \mathrm{n}){ }^{99}$ Mo reaction is presented in Fig. 1. It is evident, that the product isotope is substantially nonuniformly distributed over the volume of the target. Thus the main task is the option of the technology parameters to provide the optimum ratio of the gross and specific activity of the product isotope.

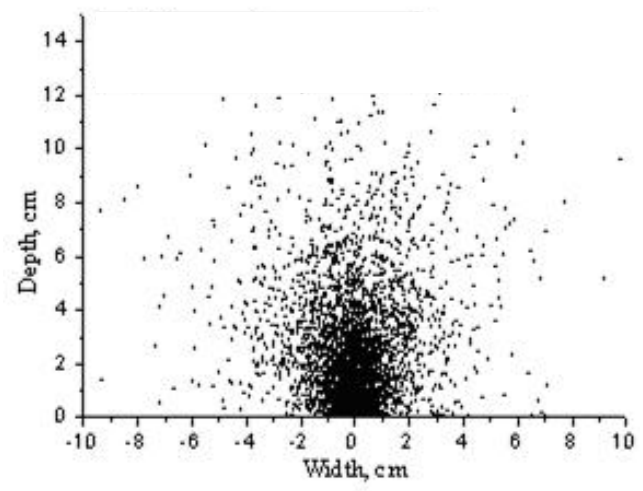

Fig. 1. Distribution of ${ }^{99}$ Mo nuclei generated with bremsstrahlung radiation

Commonly, estimation of capacity of a photonuclear technology is conducted using the results obtained at activation of a low-size experimental target. Its specific activity is normalized to the electron beam current. An estimate of productivity is based on the assumption about proportional ratio between the mass and activity of the technological and experimental targets. At the same time, such an approach seems insufficiently sub- stantiated taking into account the spatial inhomogeneity of the reaction products (see Fig. 1). So the capacity value obtained in such a way includes the considerable uncertainties connected with the size of the electron beam and target, and also with its position in the flux of the bremsstrahlung photons.

In turn, the application of Monte Carlo computation of the isotope yield is connected with the considerable timetable in view of rather low cross-section of the photonuclear reactions. Besides, the simulations require the experimental checking, because sometimes the contradictions take place in the cross-section data. The issue can be solved by introduction of a limited set of critical process parameters having the minimum of uncertainties.

In this work, a simple analytical model for description of main characteristics of a photonuclear technology of isotope production is developed, and also the methods of measuring those parameters are proposed.

\section{A MODEL}

1.1. A thick converter is commonly used for the effective transformation of energy of the accelerated electrons into bremsstrahlung radiation. In such a case, the $\mathrm{X}$-ray generation takes place at the multiple scattering of electrons in the converter. As a result, the spatial distribution of the photon flux density at the converter output for an axially symmetric electron beam can be represented in a Gaussian form with standard radial deviation $\delta_{\gamma, 0}$ and the most probable exit angle $\theta_{m}\left(E_{0}, d_{c}\right)$ depending on the electron energy $E_{0}$ and the converter thickness $d_{\mathrm{C}}[3]$.

In the photon energy span corresponding to giant dipole resonance (GDR), the dominant type of their interaction with a substance is generation of electronpositron pairs [4]. Consequently, the scattering of such photons can be neglected, specially, in the materials with low and middle Z. So any photonuclear target (in particular, a cylindrical one by radius $\mathrm{R}$ and height $\mathrm{H}$ ) can be considered as a subsystem of the half-space, when the X-ray beam escaping a converter $\mathrm{C}$ falls on its boundary (see Fig. 2). 


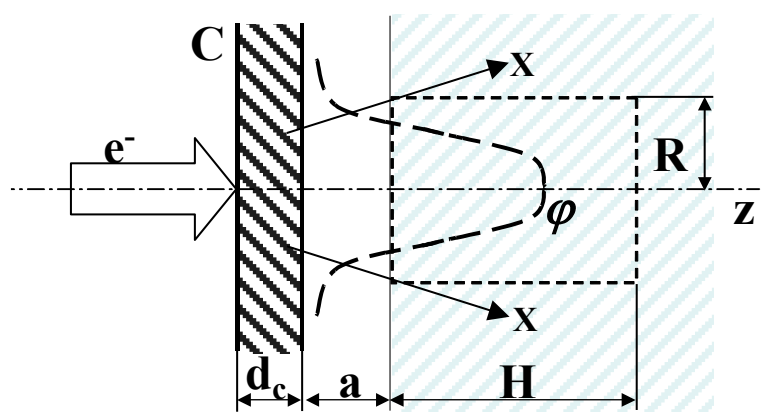

Fig. 2. Simplified schematic of photonuclear isotope production (dashed line denotes distribution of $X$-ray photon fluence $\varphi$ )

1.2. As an example, the calculated dependence of the yield $\mathrm{N}_{\gamma}$ of the bremsstrahlung photons with energy higher than 7.2 MeV (the threshold of the ${ }^{182} \mathrm{~W}(\gamma, \mathrm{n}){ }^{181} \mathrm{~W}$ reaction - the minimal value for all considered photonuclear reaction in such converter and target) normalized to the one beam electron on the converter thickness and electron energy is presented in Fig. 3.

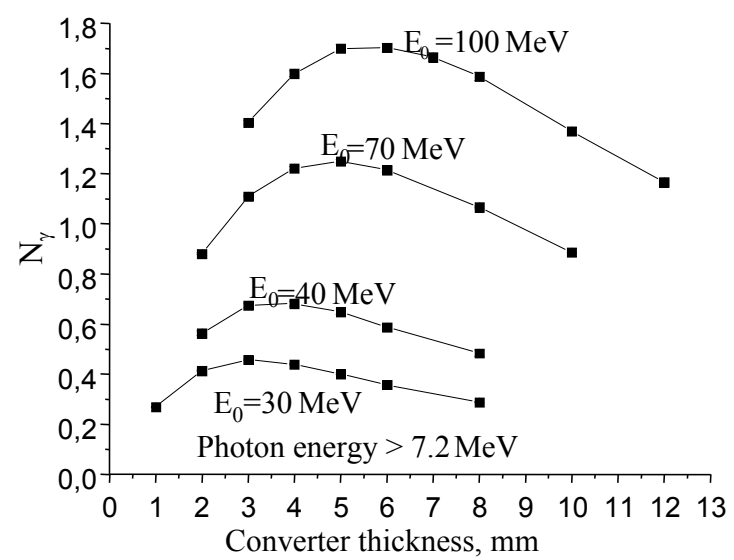

Fig. 3. Dependence of yield of above-threshold photons on thickness of $W$-converter

It is evident, that in the range $\mathrm{E}_{0}=30 \ldots 100 \mathrm{MeV}$ the value $d_{C}=4 \mathrm{~mm}$ is close to optimal. Hereinafter, a converter with such thickness was taken into consideration.

1.3. The photonuclear yield of the product nuclei in $i$-reaction normalized to the one beam electron $y_{i}$ in a target having volume $V$ can be determined by

$$
y_{i}(V)=\frac{N_{A}}{\bar{A}} v_{T} \rho_{T} \int_{V} d V \int_{E_{t h, i}}^{E_{0}} \varphi(E, \vec{r}) \cdot \sigma_{i}(E) d E
$$

where $N_{A}$ is the Avogadro number, $\bar{A}$ is the average atomic mass of the target material, $\rho_{T}$ is its density, $v_{T}$ is the relative content of the isotope-target, $\varphi(E, \vec{r})$ is the differential fluence of the X-ray photons with energy $E$ in the point of interest $\vec{r}$ normalized to the one beam electron, $\sigma_{i}(E)$ is the reaction crosssection, $E_{t h, I}$ is the threshold of the reaction.

In case of axially symmetric radiation flux, the expression for photon fluence $\varphi$ takes the form

$$
\varphi(E, r, z)=\frac{n_{\gamma}(E)}{2 \pi \delta_{\gamma}^{2}\left(E_{0}, z\right)} \exp \left\{-\left[\frac{r^{2}}{2 \delta_{\gamma}^{2}\left(E_{0}, z\right)}+\mu(E)(z-a)\right]\right\} \text {, }
$$

where $n_{\gamma}(E)$ is the spectral density of photons normalized to the one beam electron and satisfying the condition

$$
N_{\gamma}=\int_{E_{t h, i}}^{E_{0}} n_{\gamma}(E) d E_{\gamma},
$$

$\mu(E)$ is the linear photon attenuation coefficient in the target material, $\delta_{\gamma}\left(E_{0}, z\right)$ - is the standard radial deviation of the photon flux density at a distance $z$ from the converter ( $z=0$ corresponds to its rear plain),

$$
\delta_{\gamma}\left(E_{0}, z\right)=\delta_{\gamma, 0}+z \cdot \operatorname{tg} \theta_{m}\left(E_{0}\right) .
$$

For case of a pencil electron beam with standard radial density deviation $\delta_{\mathrm{e}}$, the $\delta_{\gamma, 0}$ value is given by

$$
\delta_{\gamma, 0}=\left(\delta_{e}^{2}+\Delta_{\gamma}^{2}\right)^{1 / 2},
$$

where $\Delta_{\gamma}$ - is the standard deviation of the photon fluence generated with a single electron in the converter.

The Eq.(5) enables presentation of the X-rays profile via two independent parameters: $\Delta_{\gamma}$ is determinative by geometry and material of the converter, when $\delta_{\mathrm{e}}$ by distribution of the electron beam density.

In the photon energy span corresponding to GDR, the $\mu(E)$ value is changed weakly [4]. So we will consider $\mu(E) \equiv \mu\left(E_{i}\right)$, where $E_{i}$ is the value of the photon energy in the maximum of the reaction cross-section $\sigma_{i}^{\max }$

Taking into account equation (2), the volumetric distribution of specific activity in a target produced with the electron beam at an average current $I$ for the period $t$, can be described by

$$
\dot{A}_{i}\left(E_{0}, r, z\right)=\frac{Y_{i}\left(E_{0}\right) I}{2 \pi e} \frac{\left[1-\exp \left(\lambda_{i} t\right)\right]}{\delta_{\gamma}^{2}\left(E_{0}, z\right)} \exp \left\{-\left[\frac{r^{2}}{2 \delta_{\gamma}^{2}\left(E_{0}, z\right)}+\mu\left(E_{i}\right)(z-a)\right]\right\},
$$

where $\lambda_{I}$ is the decay constant,

$$
Y_{i}\left(E_{0}\right)=\frac{N_{A}}{\bar{A}} v_{T} \int_{E_{t h, i}}^{E_{0}} n_{\gamma}(E) \cdot \sigma_{i}(E) d E .
$$

1.4. In a physical meaning, the $Y_{i}\left(E_{0}\right)$ quantity denotes the yield of the isotope-product via i-reaction in a thin wide target overlapping full photon flux and normal to its axis, normalized to the one beam electron and to the unit of the mass thickness of the target. Similarly to $\mathrm{X}$-ray converter, such a target is named as a photonuclear converter (PNC)-[5]. Accordingly, we will call $Y_{\mathrm{i}}$ as a coefficient of photonuclear conversion. Its value does not depend on the size of both the electron beam and the $\mathrm{X}$-ray flux as well as on the PNC position in the latter. So the $Y_{0}$ quantity includes the minimum of parameters affecting the uncertainty of its determination. Thus it describes the photonuclear isotope yield most accurately and so is convenient for comparison of data obtained by different techniques.

As it follows from the equation (6), the maximum of the specific activity $\dot{A}_{i}^{\text {max }}$ is located at the target front surface on the radiation flux axis and makes 


$$
\dot{A}_{i}^{\max }=Y_{i}\left(E_{0}\right) \frac{I}{2 \pi e \delta_{\gamma}^{2}\left(E_{0}, a\right)}\left[1-\exp \left(-\lambda_{i} t\right)\right]
$$

$$
\frac{d A_{i}}{d z}=Y_{i}\left(E_{0}\right) \frac{I \rho_{T}}{e} \cdot\left[1-\exp \left(-\lambda_{i} t\right)\right]\left\{1-\exp \left[-\frac{R^{2}(z)}{2 \delta_{\gamma}^{2}\left(E_{0} z\right)}\right]\right\} \exp \left[-\mu\left(E_{i}\right)(z-a)\right]
$$

It should be noted that the equation (9) is valid for any axially symmetrical target.

As it is evident from the equations (2) and (6), the photon flux density and, consequently, the rate of the isotope generation at side and rare surfaces of a target decreases sharply with the increase of the target size $\mathrm{R}>\delta_{\gamma}\left(E_{0}, a\right), H>\mu^{-1}\left(E_{i}\right)$. Hence it follows, that optimal target dimensions in regard to the ratio of its gross to specific activity should meet the conditions $\mathrm{R} \sim \delta_{\gamma}(a)$, $\mathrm{H}<\mu^{-1}\left(E_{i}\right)$.

1.5. It has been shown in [3], that the normalized spectral yield of X-rays from a thick converter can be described with the uncertainty not higher than $10 \%$ by a simple expression

$$
n_{\gamma}(E)=2 \eta\left(E_{0}\right)\left(E^{-1}-E_{0}^{-1}\right),
$$

where $\eta$ is the coefficient of the energy conversion of electron into bremsstrahlung radiation.

For a GDR case, the $\sigma_{i}(E)$ cross-section can be presented in a Breit-Wigner form [6]

$$
\sigma_{i}(E)=\sigma_{i}^{\max }\left(E \Gamma_{i}\right)^{2} /\left[\left(E^{2}-E_{i}^{2}\right)+\left(E \Gamma_{i}\right)^{2}\right],
$$

where $\Gamma_{I}$ is FWHM of the $i$-reaction excitation function. Hence, the expression (7) can be reduced to the form

$$
Y_{i}\left(E_{0}\right)=2 \frac{N_{A}}{\bar{A}} v_{T} \eta\left(E_{0}\right) \cdot \sigma_{i}^{\max } \cdot S\left(E_{0}\right),
$$

where the $S_{i}\left(E_{0}\right)$ factor reveals a weak dependence on the target material. E.g. for the ${ }^{100} \mathrm{Mo}(\gamma, \mathrm{n}){ }^{99}$ Mo reaction, the $S_{i}\left(E_{0}\right)$ value ranges from $0.25(40 \mathrm{MeV})$ to 0.35 $(100 \mathrm{MeV})[7]$.

\section{BENCHMARKING}

\subsection{METHODS}

The coefficient of photonuclear conversion $Y_{i}$ can be determined experimentally through measuring the activity of a PNC target by

$$
Y_{i}=\frac{e \cdot A_{P N C}}{I_{c} \cdot T_{m} \cdot\left[1-\exp \left(-\lambda_{i} t_{c}\right)\right]},
$$

where $A_{P N C}$ is the activity of PNC generated at an electron beam mean current of $I_{c}$ for the irradiation time $t_{c}$, $T_{m}$ is the mass thickness of PNC.

The standard radial deviation (SDR) of the photon flux density $\delta_{\gamma}(\mathrm{z})$ can be measured by activation of a stack comprising two foils - PNC and a small circular foil by radius $R_{S} \sim \delta_{\gamma}(\mathrm{z})$, positioned normally and axially symmetrically to the photon flux, by

$$
\delta_{\gamma}(z)=R_{S}\left[-2 \ln \left(1-A_{S} / A_{P N C}\right)\right]^{-1 / 2},
$$

where $A_{S}$ is the activity of the small foil.

The most probable exit angle of the above-threshold photons from the converter, $\theta_{m}\left(E_{0}\right)$, can be determined from the measured dependence $\delta_{\gamma}(z)$, e.g. by activation of two PNC positioned at different distances $z$ from the converter and measuring SRD of their radial activity distribution.

\subsection{RESULTS AND DISCUSSION}

2.2.1. The experimental testing of the analytical model was performed using the ${ }^{100} \mathrm{Mo}(\gamma, \mathrm{n}){ }^{99}$ Mo reaction having the well-established cross-section (Fig. 4).

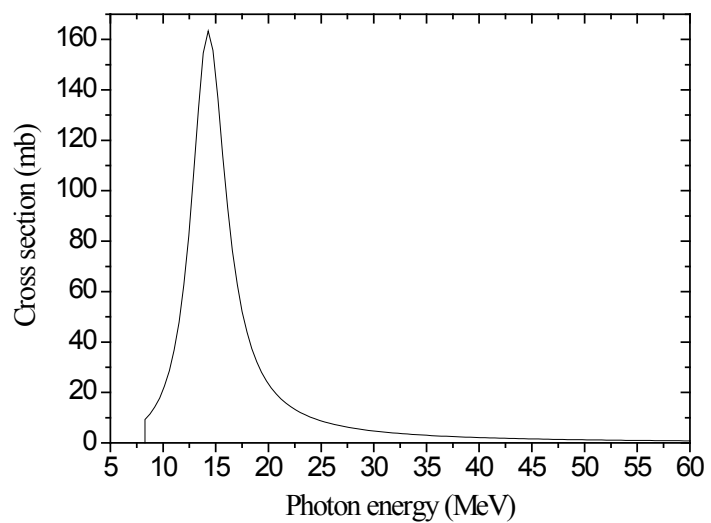

Fig. 4. Cross-section of the ${ }^{100} \mathrm{Mo}(\gamma, n)^{99}$ Mo reaction

The pairs of circular axially aligned foils from natural molybdenum each $0.1 \mathrm{~mm}$ thick, and also by 25 and $6 \mathrm{~mm}$ in diameter, respectively, were used. The activation of foils was performed at a LU-40m electron Linac of NSC KIPT [8]. As a converter of bremsstrahlung radiation, the four plates from tantalum each $1 \mathrm{~mm}$ thick and cooled with water were used. After activation at a specified electron energy $\mathrm{E}_{0}$ and cooling, the measurement of induced ${ }^{99} \mathrm{Mo}$ activity of the foils at gamma-line of $739.5 \mathrm{keV}$ (the branch ratio is $12.2 \%$ ) was performed. The values obtained were reduced to the end of irradiation, $1 \mu \mathrm{A}$ of the electron beam current and $1 \mathrm{~h}$ of exposure. The uncertainty of the activity measurement was estimated as less than $10 \%(\mathrm{k}=2)$. Hence the value of the coefficient of photonuclear conversion $Y_{i}^{\exp }$ and SRD of the photon flux density were determined using the equations (13), (14), and also the estimate of the maximum of specific activity $\dot{A}_{i, \exp }^{\max }$ was obtained (see Table). For comparison, the values of $Y_{i}^{\text {calc }}$ and $\dot{A}_{i, \text { calc }}^{\max }$ calculated with the use of equations (12) and (8) respectively, are given in the Table as well.

2.2.2. It is evident from the data obtained, that the calculated and measured values of $Y_{\mathrm{i}}\left(E_{0}\right)$ are agreed within $10 \ldots 15 \%$ depending on the electron energy $E_{0}$. The accuracy is determined by the precision of representation of the convolution $\int_{E_{t h}}^{E_{0}} n_{\gamma}(E) \sigma(E) d E$ with the use of introduced form of the X-ray spectrum (10), and also by the Breit-Wigner approximation for the GDR cross-section (11). 
Yield of ${ }^{99}$ Mo in the pairs of circular Mo-foils activated by high-energy X-rays

\begin{tabular}{|l|c|c|c|c|c|c|c|}
\hline $\mathrm{E}_{0}, \mathrm{MeV}$ & $\begin{array}{c}\mathrm{A}_{\mathrm{PNC}}, \\
\mathrm{kBq} / \mu \mathrm{A} \cdot \mathrm{h}\end{array}$ & $\begin{array}{c}\mathrm{A}_{\mathrm{S}}, \\
\mathrm{kBq} / \mu \mathrm{A} \cdot \mathrm{h}\end{array}$ & $\begin{array}{c}\delta_{\gamma}, \\
\mathrm{mm}\end{array}$ & $\begin{array}{c}Y_{i}^{\exp }, \\
\mathrm{cm}^{2} / \mathrm{g}\end{array}$ & $\begin{array}{c}Y_{i}^{\text {calc }}, \\
\mathrm{cm}^{2} / \mathrm{g}\end{array}$ & $\begin{array}{c}\dot{A}_{i, \exp }^{\max } \\
\mathrm{kBq} / \mathrm{g} \cdot \mu \mathrm{A} \cdot \mathrm{h}\end{array}$ & $\begin{array}{c}\dot{A}_{i, c a l c}^{\max }, \\
\mathrm{kBq} / \mathrm{g} \cdot \mu \mathrm{A} \cdot \mathrm{h}\end{array}$ \\
\hline $\mathbf{4 0}$ & 103.6 & 14.6 & 5.5 & $1.5 \cdot 10^{-5}$ & $1.7 \cdot 10^{-5}$ & $5.6 \cdot 10^{2}$ & $6.3 \cdot 10^{2}$ \\
\hline $\mathbf{4 8}$ & 128.5 & 25.1 & 4.5 & $1.9 \cdot 10^{-5}$ & $2.2 \cdot 10^{-5}$ & $9.7 \cdot 10^{2}$ & $1.5 \cdot 10^{3}$ \\
\hline $\mathbf{6 0}$ & 151.2 & 36.7 & 4.0 & $2.3 \cdot 10^{-5}$ & $2.5 \cdot 10^{-5}$ & $1.4 \cdot 10^{3}$ & $2.3 \cdot 10^{3}$ \\
\hline $\mathbf{7 0}$ & 168.4 & 52.3 & 3.4 & $2.5 \cdot 10^{-5}$ & $2.7 \cdot 10^{-5}$ & $2.0 \cdot 10^{3}$ & $3.4 \cdot 10^{3}$ \\
\hline $\mathbf{8 0}$ & 183.7 & 87.5 & 2.7 & $2.8 \cdot 10^{-5}$ & $2.9 \cdot 10^{-5}$ & $3.5 \cdot 10^{3}$ & $6.2 \cdot 10^{3}$ \\
\hline
\end{tabular}

The calculated values of the maximum of the specific activity $\dot{A}_{i, \text { calc }}^{\max }$ are higher than those measured, and the difference increases with the growth of $E_{0}$. It becomes clear considering that the equation (8) for $\dot{A}_{i}^{\max }$ is related to its value on the axis of the photon flux, when $\dot{A}_{i, \exp }^{\max }$ was measured as an average specific activity $\dot{A}_{s}$ of the small target by $6 \mathrm{~mm}$ in diameter. As $\delta_{\gamma}$ becomes lower with the increase of electron energy $\mathrm{E}_{0}$, the photon flux nonuniformity at the target and the difference between its specific activity on the axis and at the periphery increases.

2.2.3. For the experimental check of the results, obtained for a thick production target by a simulation technique, the activation of a target comprising 8 stacked disks from natural molybdenum each by $20 \mathrm{~mm}$ in diameter and $3.09 \mathrm{~mm}$ thick by a $(40 \mathrm{MeV} ; 4.0 \mu \mathrm{A})$ electron beam for $0.5 \mathrm{~h}$ was conducted.

In Fig. 5, the results of measurement of the induced ${ }^{99} \mathrm{Mo}$ activity in the disks, and also the activity distribution along the target axis obtained by MC simulation (solid curve) and by calculation (dashed curve) using the equation (8) are presented. It is seen, that both of the calculated dependences are in good agreement with the experimental data. At the same time, the curve obtained from the equation (8) is shifted sideways the growth of the activity. It can be explained by greater calculated value of the $Y_{\mathrm{i}}$ coefficient as compared with the measured one (see Table).

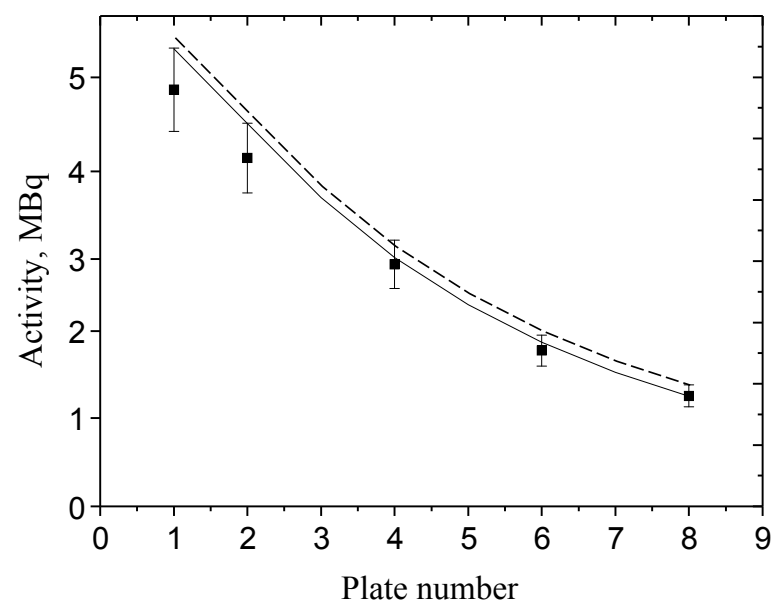

Fig. 5. Distribution of ${ }^{99}$ Mo activity along stack of disks from natural molybdenum

\section{CONCLUSIONS}

Accuracy of estimation of the photonuclear isotope yield in a thick production target is governed by a set of process characteristics, which can be arbitrary subdivided into three groups, namely:

- specified parameters (electron energy, current and size of the beam, material and geometry of a converter, distance from converter to target, its geometry and isotopic composition, etc);

- referenced data (reaction threshold and crosssection, photon attenuation coefficient);

- derivative from the first two the critical parameters of technology (coefficient of photonuclear conversion,standard radial deviation of the profile of the above-threshold photon flux at a target and the most probable angle of the photon escape from a converter).

The established critical parameters contain minimum of uncertainties and can be readily measured in experiment. The analytical model based on usage of those parameters enables prompt estimate of specific and gross activity of a production target, and so optimization of its geometry and activation regime.

Coefficient of photonuclear conversion enters as a factor in all expressions of the model describing the target activity and its volumetric distribution. Measurement of this coefficient is much easier procedure with a much fewer number of uncertainties as compared with the determination of cross-section of a photonuclear reaction. The coefficient increases almost linear with the electron energy $E_{0}$. At the same time the maximum of the specific activity grows approximately proportionally to $E_{0}^{3}$.

Considering nonuniformity and divergence of the Xray beam, the estimation of capacity of photonuclear technology on the basis of data on specific activity of a small experimental target can be insufficiently accurate.

\section{REFERENCES}

1. N.P. Dikiy, A.N. Dovbnya, Yu.V. Lyashko, E.P. Medvedeva, Yu.D. Tur, V.L. Uvarov, I.D. Fedorets, S.A. Pashchuk, I.G. Evseev. Production of Medical Isotopes at Electron Accelerators // Problems of Atomic Science and Technology. Series “Nuclear Physics Investigations". 2000, № 2, p. 58-61.

2. N.I. Ayzatskiy, N.P. Dikiy, A.N. Dovbnya, Yu.V. Lyashko, V.I. Nikiforov, B.I. Shramenko, A.Eh. Tenishev, A.V. Torgovkin, V.L. Uvarov. Comparison of $\mathrm{Cu}-67$ Production at Cyclotron and Electron Accelerator // Proc. of Conf. on Cyclotron 
and their Applications (Cyclotrons 2007, Sept. 30Oct. 5, 2007, Giardini Naxos, Italy), p. 243-245.

3. V.I. Nikiforov, V.L. Uvarov. Estimation of the Photonuclear Yield of Isotopes in Production Targets // Radiochemistry. 2010, v. 52, № 3, p. 315-321.

4. J.H. Hubbel. Photon Mass Attenuation and Energyabsorption Coefficients from $1 \mathrm{keV}$ to $20 \mathrm{MeV} / /$ Int . J. Appl. Radiat. Isot. 1982, v. 33, p. 1269-1290.

5. S.P. Karasyov, V.I. Nikiforov, R.I. Pomatsalyuk, V.A. Shevchenko, I.N. Shlyakhov, A.Eh. Tenishev, V.L. Uvarov, Yu.V. Zhebrovsky. High-Intensity Brems strahlung Monitoring System for Photonuclear Technologies // Proc. of EPAC 2006 (Edinburgh, Scotland, 2006), p. 1235-1237.
6. Handbook on photonuclear data for Applications // Final report of coordinated researched projects. IAEA. TECDOC. Draft N 3 (Culham). 11 February 2000.

7. V.I. Nikiforov, V.L. Uvarov. A method for estimation of isotope yield in a thick target under photonuclear production //NIM. 2011, B 269, p. 31493152.

8. N.I. Ayzatsky, V.I. Beloglazov, V.P. Bozhko, et al. Electron $100 \mathrm{MeV}$ Linac Based Facility to NuclearPhysical Experimental Investigation // Problems of Atomic Science and Technology. Series "Nuclear Physics Investigations”. 2010, № 2, p. 18-21.

Article received 11.10.2019

\section{О КРИТИЧЕСКИХ ПАРАМЕТРАХ ФОТОЯДЕРНОГО ПРОИЗВОДСТВА ИЗОТОПОВ}

\section{В.Л. Уваров}

Предложена аналитическая модель для описания генерации изотопов в толстой технологической мишени под воздействием пространственно-неоднородного потока высокоэнергетичного тормозного излучения. Установлен набор основных параметров процесса, определяющих выход целевого изотопа и распределение его удельной активности в мишени. Показано, что такими параметрами могут являться нормированный на массовую толщину выход изотопа в тонкой мишени, перекрывающей поток тормозных фотонов (коэффициент фотоядерной конверсии), а также стандартное отклонение радиального распределения плотности потока надпороговых фотонов на мишени и наиболее вероятный угол их вылета из конвертера. Описаны методы измерения этих параметров. На примере реакции ${ }^{100} \mathrm{Mo}(\gamma, \mathrm{n}){ }^{99}$ Мо проведено тестирование модели путем сравнения полученных на ее основе данных с результатами экспериментального исследования и компьютерного моделирования. Предложенный подход позволяет производить оптимизацию фотоядерной технологии производства изотопов в отношении размеров мишени и режима ее активации.

\section{ПРО КРИТИЧНІ ПАРАМЕТРИ ФОТОЯДЕРНОГО ВИРОБНИЦТВА ІЗОТОПІВ}

\section{В.Л. Уваров}

Запропоновано аналітичну модель для опису генерації ізотопів у товстій технологічній мішені під дією просторово-неоднорідного потоку високоенергетичного гальмівного випромінення. Встановлено набір основних параметрів процесу, що визначають вихід цільового ізотопу і розподіл його питомої активності в мішені. Показано, що такими параметрами можуть бути нормований на масову товщину вихід цільового ізотопу в тонкій протяжній мішені, яка перекриває потік гальмівних фотонів (коефіцієнт фотоядерної конверсіі), а також стандартний радіальний відхил розподілу щільності потоку надпорогових гальмівних фотонів на мішені і найбільш вірогідний кут їх вильоту з конвертера. Описані методи вимірювання цих параметрів. На прикладі реакції ${ }^{100} \mathrm{Mo}(\gamma, \mathrm{n}){ }^{99}$ Мо проведено тестування аналітичної моделі шляхом експериментального дослідження і комп'ютерного моделювання. Запропонований підхід дозволяє проводити оптимізацію фотоядерної технології відносно розмірів мішені і режиму іiі активації. 